\title{
Serial-position effects in infants' recognition memory
}

\author{
EDWARD H. CORNELL and LINDA I. BERGSTROM \\ University of Alberta, Edmonton, Alberta, Canada
}

\begin{abstract}
Preverbal infants (7 months of age) were repeatedly shown a fixed series of photographs of adult female faces. The effects of the order of presentation of a photo (first, middle, or last) and the duration of retention $(5 \mathrm{sec}, 1 \mathrm{~min}$, or $5 \mathrm{~min}$ ) were subsequently assessed in a proberecognition test. Both primacy and recency effects were obtained, but there was no evidence of recognition of the face that appeared in the middle of the series. There was also no evidence of recognition of the most recently studied face following the 5-min retention interval. The bowed serial-position function and labile recency effect match those found in the performance of older subjects in classical verbal learning tasks, and we suggest an automatic process underlying these effects. Our explanation emphasizes differential learning and the context of the items to be remembered.
\end{abstract}

It has generally been acknowledged since antiquity that human learning, memory, and the organization of ideas are affected by the temporal succession of experience. Hence, one of the first problems for experimental psychology was to describe and explain the lawful relations between the order of events and their mental representation. Ebbinghaus (1885/1964) is credited with the isolation of one of the most prevalent relations, the serial-position effect. The serial-position effect occurs when an item (word, picture, or action) to be remembered appears in an invariant sequence of other items (a list). Learning and memory of the item are related to its serial position in the list-if it occurs in the middle of the sequence, it is less likely to be remembered than if it occurs at the beginning or the end. The advantage at the beginning of a list is termed "the primacy effect," and the advantage at the end of a list is termed "the recency effect."

Crowder (1976) recently reviewed several explanations for these effects, and in the present analysis we focus on two dimensions used by Crowder to categorize these explanations. First, there are explanations that maintain that a single process is responsible for both the primacy and the recency effects, and there are twoprocess explanations that describe separate mechanisms. Second, there are explanations that emphasize passive or automatic processes and other explanations that emphasize strategic or semantic cognition.

This research was supported by Grant A0267 to E. Cornell from the Natural Sciences and Engineering Research Council of Canada. We thank Janet Royce for her help in testing babies and Jan Goodsitt for her help with the manuscript. We gratefully acknowledge the hospitality and support provided by the Institute of Child Development while we prepared this report. Requests for reprints should be addressed to Edward $\mathrm{H}$. Cornell, Department of Psychology, University of Alberta, Edmonton, Alberta T6G 2E9, Canada.
As indicated in Crowder's (1976) review, these dimensions may be combined in various ways. For example, the "positional-stimulus distinctiveness" hypothesis suggests a single automatic process. The idea is that each item on a list is associated with a representation of an order, and the ends of the list are distinctive. In contrast, a familiar two-process explanation suggests that the primacy effect is due to rehearsal strategies, with items occurring early in the list receiving more processing than items near the end of the list. The recency effect, then, is usually attributed to a nonstrategic process, the automatic but short-term persistence of the present in consciousness.

In the study that follows, we tested for the effects of serial position in the recognition performance of 7-month-old infants. The study of preverbal infants provides unique results bearing on process theories (e.g., Rovee-Collier \& Sullivan, 1980; Strauss, 1979; for a review, see Cornell, 1983). For example, we can assume these subjects do not initiate mnemonics such as naming and rehearsal. Thus, if their performance indicates a primacy effect, it may be preferable to consider explanations that emphasize passive factors, such as interference, differential learning of items, or the previously mentioned positional-stimulus distinctiveness. In addition, it is conceivable that the mechanisms of infant memory are fundamental, perhaps being invariant across development or serving as the basis for the later operation of aware and planful mnemonics.

There have been few attempts to assess infants' memory for more than a single item. Olson (1979) presented four different visual patterns for 4-monthold infants to study, but there was little evidence that these babies remembered what they had seen. He assessed recognition memory by using a probe technique in which a pattern that had occurred in the first, second, third, or fourth position in the sequence was subse- 
quently paired with a completely new pattern. This pairing takes advantage of the infants' tendency to selectively fixate novel visual events; it is analogous to a two-choice recognition test in which recognition is incidentally indicated by relatively less attention to the previously studied stimulus. Infants' preferences for the novel of two stimuli are consistent when habituation has accrued to the familiar stimulus (Hunter, Ross, \& Ames, 1982; Rose, Gottfried, Melloy-Carminar, \& Bridger, 1982). Yet Olson (1979, Experiment 1) noted only tenuous primacy and recency effects in the babies' recognition performance, an unusual finding, since infants' novelty preferences following visual study of a single picture can be quite robust (e.g., Fagan, 1973; see reviews by Olson, 1976, and Werner \& Perlmutter, 1979). There may be several possible reasons for this discrepancy, but we noted that Olson's learning procedure included only a single brief exposure of the items to be remembered. In the present study, we attempted to ensure familiarity in two ways. Infants received multiple presentations of an invariant list of stimuli (repeated habituation; see Wagner \& Pfautz, 1978), and each list presentation was separated by a study break (temporal spacing; see Cornell, 1980).

Finally, we tested recognition either immediately after the learning procedure or after short delays. One of the most interesting results of research on the serialposition curve is that primacy and recency effects may be differentially affected when a retention interval and interpolated materials occur between learning and free recall of a list (Crowder, 1976). The result is counterintuitive; memories of the most recent items are erased, whereas the recollection of the items at the beginning of the list appears to be unchanged. The selective effect of distraction on recency has strengthened the notion that there is a separate process (such as rehearsal) underlying primacy. Our procedure allowed us to pose the question to preverbal infants: What is the effect of delay on memory for items that occur at different serial positions?

\section{METHOD}

\begin{abstract}
Subjects
Two hundred and sixty-two healthy babies were tested in their homes. All were born following full-term pregnancy (36-41 weeks' gestation). Their names were obtained from birth announcements published in the local newspaper. A form letter was mailed to the parents to solicit participation. Interested parents called in. Others receiving letters were contacted by telephone to describe the procedures and to schedule appointments. The data from 46 tests were replaced, 9 because of equipment failures, 11 because of experimenter errors, and 26 because the infant's lack of interest or its fussiness precluded the completion of the test procedure. All infants were between 26 and 32 weeks of age (median $=28$ weeks). There were equal numbers of boys and girls assigned to all subgroups within the study.
\end{abstract}

\section{Apparatus and Materials}

A portable looking chamber was assembled in the living room. The looking chamber was devised by Fantz (Fantz \&
Nevis, 1967), and a photograph of it is provided in Miranda (1970). Essentially, it is a wooden box about the size of a large orange crate. The box is mounted on legs and is open on one side. The open side is positioned such that the baby's face is inside the box while he or she is sitting on the mother's lap. The interior of the box is lined with a homogeneous gray felt. Directly in front of the baby (approximately $35 \mathrm{~cm}$ from his or her nose) is a frontlit stage. At the beginning of a trial, the stage rotates in to present two plaques; each of these plaques provides a mount for a semigloss photograph. The photos reflect light, whereas the interior walls and stage absorb light. This arrangement produces a small reflection of the photos on the baby's eye. An observer is seated behind the stage and can see the reflections by peering through a $.7-\mathrm{cm}$-diam peephole positioned midway between the photos. The photos are separated by $15 \mathrm{~cm}$, such that when the baby looks at one, his or her head and/or eyes are rotated off midline. The observer can see the photo the baby is fixating over the center of the pupil of the closest eye (the fixation response is illustrated by Fantz, 1966). The observer does not have to identify the photo from this reflection, however. The observer monitors only whether the baby is looking and whether it is looking to the left or the right. A record is produced when a pole switch is moved in the direction of fixation. The switch is attached to a portable event recorder, which is activated at the start of a trial. Electronic timers are also activated and provide a signal to the observer when a trial has been completed. The observer then rotates the stage out of the interior, and photographs can be exchanged and the next trial can be initiated within 3-7 sec.

In this experiment, the stimuli were achromatic photographs of women's faces, posed smiling at a fixation point $45 \mathrm{deg}$ from the camera. Similar three-quarter poses are illustrated by Fagan (1976), who noted high recognition performance by infants who had studied such representations. We used eight photos: two identical copies of each of four faces. The faces measured approximately $13 \mathrm{~cm}$ from chin to hairline, and they appeared in front of a homogeneous white background, cropped $18 \mathrm{x}$ $15 \mathrm{~cm}$.

\section{Procedure}

Each infant was presented a familiarization sequence, followed by a retention interval and a recognition test.

The familiarization sequence consisted of four identical list presentations separated by 1 -min interstudy intervals. A list consisted of three trials, each presenting a different face side by side with its copy. During each trial, the infant could look at either of the identical photos to accumulate $5 \mathrm{sec}$ of study. Thus, each trial was of variable duration-sometimes the baby stared at a photo, and sometimes he or she examined the apparatus. In contrast with the 1-min interstudy intervals, trials were separated by 3-7 sec, the time necessary to change photos. The looking chamber was pulled away from the baby immediately after the photos had been withdrawn for the interstudy interval. This prevented the baby's becoming restless in the homogeneous interior of the apparatus; the baby was free to look around the room. Then the apparatus was repositioned for the next blocked series of trials. Thus, at the end of the familiarization sequence, each infant had been observed studying each of the faces for the same period of time, a total of 20 sec of fixation per face.

A retention interval followed the fourth list presentation. Seventy-two infants were assigned to one of three retention intervals: $5 \mathrm{sec}, 1 \mathrm{~min}$, or $5 \mathrm{~min}$. The apparatus was quickly withdrawn and repositioned to constitute the 5-sec retention interval. A similar procedure was used during the 1 - and 5-min delays; while outside the looking chamber, the baby remained on the mother's lap.

A probe-recognition test followed this retention interval. Of the infants who had experienced a particular retention interval, 24 were assigned to one of three probe tests. For these tests, a photo that had consistently occupied either the first, the middle, 
or the last position in the list was paired with a completely new photo for $5 \mathrm{sec}$. The previously exposed and the novel photo were then withdrawn for 3-7 sec, their left-right positions were interchanged, and they were presented for another $5 \mathrm{sec}$. The purpose of this transposition was to counteract any bias to gaze at a particular location.

In constructing the sequence of stimuli to be used, across infants each photograph was assigned equally often to each serial position in the list and as the novel target during the recognition test. This was done to ensure that preferences to look at any particular face would not be systematically associated with order of study or retention interval. As previously indicated, the list consisted of three items, the minimal length for assessing serial-position effects. This short sequence was used because Olson (1979) had found that infants had difficulty remembering any one of a series of four items.

Looking behavior was recorded by two observers who were experienced with the apparatus and testing procedures. Interobserver reliability (simultaneous recording of responses) had been checked on two separate occasions before the study began. Based on pilot work involving 11 infants who received recognition tests identical to those in the present study, the Pearson coefficient of correlation between observed fixation times was .93, with almost identical totals for mean fixation times recorded by the two observers. This agreement is typical in laboratories using the same apparatus and measurement procedures (see Fagan, 1976, and Rose et al., 1982).

\section{RESULTS}

Figure 1 illustrates the pattern of the infants' looking during the familiarization sequence. Each point represents the temporal duration of a trial, or the time necessary to expose a face to ensure that the baby had looked at it for $5 \mathrm{sec}$. In this form, the functions are the inverse of the familiar decrements representing habituation. The main effects of study trial and serial position on duration of exposure were apparent in a $4 \times 3$ repeated-

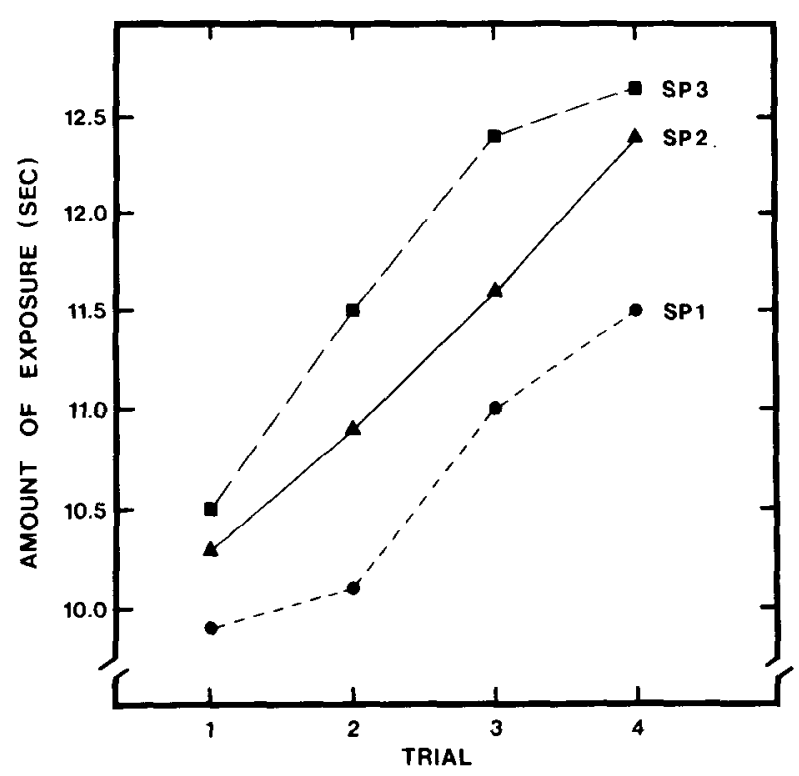

Figure 1. Length of exposure of photos required during familiarization trials as a function of serial position (SP). A trial was terminated when an infant had looked at a photo for 5 sec. Each point represents the mean for 216 infants. measures analysis of variance $[\mathrm{F}(3,645)=23.19$ and $\mathrm{F}(2,645)=5.15$, respectively; $\mathrm{MSe}=54.42$, ps $<.01]$. In sum, when the babies studied faces ordered in distributed blocks, the attractiveness of the faces appeared to wane in a monotonic fashion, both within and across blocks. The subsequent recognition tests indicated that the response decrement to the repeated items was not due solely to nonspecific fatigue; the infants were sufficiently alert to detect the introduction of the novel test photo. At this point, we can note simply that more total time was taken to study the face that appeared in the third serial position than the face that appeared in the first. These data are important when the possible relations between patterns of learning and retention for items in different serial positions are considered.

Table 1 summarizes the infants' looking behavior on the subsequent recognition tests. At this age, recognition is inferred from the infants' tendency to selectively attend to a new picture when it appears next to one previously studied (Fantz, Fagan, \& Miranda, 1975). Hence, the $p$ values noted in Table 1 are for a comparison of the $t$ values for differences between the percentage of total fixation on the novel photo and a chance value of 50\%. All $p$ values mark a reliable novelty preference, as indicated by one-tailed tests.

The percent response to the novel photo was subjected to a $2 \times 4 \times 3 \times 3$ analysis of variance, including the factors of sex, test stimulus, serial position, and retention interval. The main effect of serial position was marginal $[F(2,144)=2.66, \mathrm{MSe}=.049, \mathrm{p}=.07]$. There was one interaction, involving the factors of test stimulus, serial position, and retention interval $[\mathrm{F}(12,144)=$ $1.92, \mathrm{p}<.05]$. The interaction was uninterpretable.

We tested for the presence of a nonmonotonic serialposition effect at each of the retention intervals. A Ushaped curve was confirmed at the shortest delay. There was a significant quadratic trend $[F(1,144)=3.38$, $\mathrm{MSe}=.056, \mathrm{p}<.05$, one-tailed test $]$ and a nonsignificant residual $[\mathrm{F}(1,144)=0.24]$ when the probe-recognition test followed $5 \mathrm{sec}$ after the last study period. The quadratic component was not reliable at the 1- and 5 -min retention intervals $[\mathrm{F}(1,144)=0.94, \mathrm{MSe}=.050$, and $\mathrm{F}(1,144)=0.57, \mathrm{MSe}=.050$, respectively $]$.

As can be seen in Table 1, there was substantial variability in the infants' recognition performance following the blocked study of three photos of female faces. Nevertheless, there was consistent evidence of recognition of the face that appeared at the beginning of the series and no evidence of recognition of the face that appeared in the middle. The pattern of results appears to be similar when tests occurred $5 \mathrm{sec}$ or 1 min after familiarization, but only the former were consistent with a bowed serial-position function.

One source of the dissolution of the quadratic trend is indicated in Table 1: There was no evidence of recognition of the face that occurred at the third serial position when the infants were tested after a 5-min 
Table 1

Total Duration (in Seconds) of Looking at Both Faces and Percentage Allocated to Novel Face During Recognition Tests

\begin{tabular}{|c|c|c|c|c|c|c|}
\hline & \multicolumn{6}{|c|}{ Retention Interval } \\
\hline & \multicolumn{2}{|c|}{5 Seconds } & \multicolumn{2}{|c|}{1 Minute } & \multicolumn{2}{|c|}{5 Minutes } \\
\hline & $\begin{array}{c}\text { Total } \\
\text { Duration }\end{array}$ & $\begin{array}{l}\text { Percentage } \\
\text { Allocated }\end{array}$ & $\begin{array}{c}\text { Total } \\
\text { Duration }\end{array}$ & $\begin{array}{l}\text { Percentage } \\
\text { Allocated }\end{array}$ & $\begin{array}{c}\text { Total } \\
\text { Duration }\end{array}$ & $\begin{array}{l}\text { Percentage } \\
\text { Allocated }\end{array}$ \\
\hline & \multicolumn{6}{|c|}{ Serial Position 1} \\
\hline $\mathrm{SD}$ & 2.1 & 26 & 1.5 & 25 & 1.7 & 19 \\
\hline $\mathbf{M}$ & 3.1 & 64 & 2.1 & 60 & 2.8 & 64 \\
\hline \multirow[t]{2}{*}{$t$} & & $2.31^{*}$ & & $1.79 *$ & & $2.92 * *$ \\
\hline & \multicolumn{6}{|c|}{ Serial Position 2} \\
\hline SD & 1.9 & 27 & 1.5 & 23 & 1.7 & 25 \\
\hline $\mathbf{M}$ & 2.9 & 55 & 2.4 & 54 & 2.5 & 54 \\
\hline \multirow[t]{2}{*}{$t$} & & 0.83 & & 0.79 & & 0.85 \\
\hline & \multicolumn{6}{|c|}{ Serial Position 3} \\
\hline SD & 1.7 & 16 & 1.6 & 19 & 1.4 & 23 \\
\hline $\mathbf{M}$ & 3.1 & 67 & 2.4 & 59 & 2.6 & 53 \\
\hline$t$ & & $3.58 * *$ & & $1.98^{*}$ & & 0.59 \\
\hline
\end{tabular}

Note-Each cell represents 24 infants. The t values represent a comparison of the obtained percentage of fixation on the novel photo and a chance value of $50 \% . S D=$ standard deviation; $M=$ mean. $\quad{ }^{*} p<.05$, one-tailed test. $\quad{ }^{* *} p<.01$, one-tailed test.

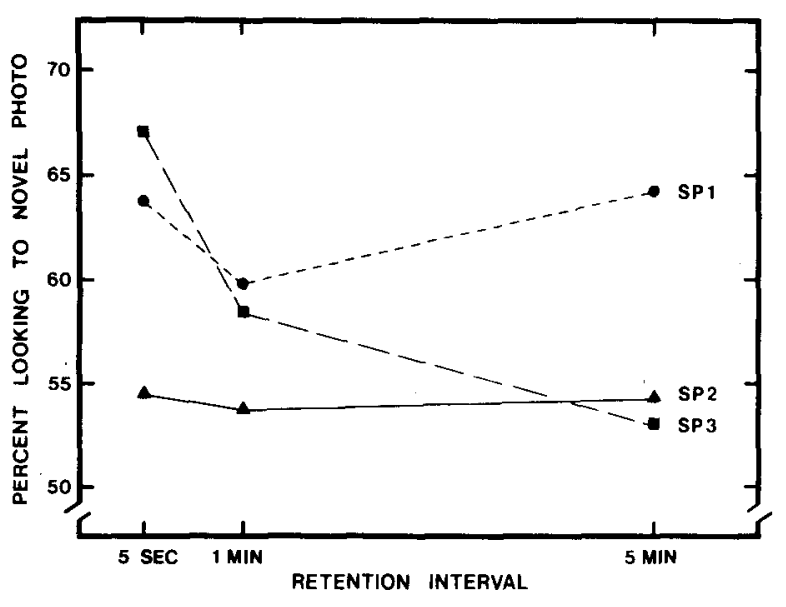

Figure 2. Percent fixation to novel photo on immediate and delayed recognition tests as a function of serial position (SP) of familiarized photo. Each point represents the mean for 24 infants.

retention interval. Analyses of variance indicated that the delay factor had no effect on performance with items at the beginning and middle of the list $[F(2,69)=$ $0.28, \mathrm{MSe}=.055$, and $\mathrm{F}(2,69)=.01$, MSe $=.064$, respectively], but did affect the recognition response to the face that appeared at the end of the list $[\mathrm{F}(2,69)=$ $3.27, \mathrm{MSe}=.038, \mathrm{p}<.05]$. Figure 2 contains the functions representing the effect of delay on memory for items in each of the serial positions.

\section{DISCUSSION}

This experiment found study and test conditions that indicate serial-position effects in the learning and memory processes of infants (infans, Latin, incapable of speech). It is instructive to compare their performance with that of older subjects in verbal learning tasks.

For example, older children and adults are usually instructed to study lists, or they are in school or laboratory situations in which they suspect that their performance will be tested. They often employ deliberate mnemonics. In contrast, the babies learned as a result of their natural interest in the visual surround. The index of their learning and retention was also incidental; it happens they spent relatively less time looking at something previously seen. Thus, we favor explanations compatible with the idea that the mechanisms underlying serial-position effects are automatic.

This bias does not preclude that serial-position effects can be affected by cognitive operations such as naming, rehearsal, or counting backwards after study. Our position is that such processes serve to augment, maintain, or attenuate more fundamental passive mechanisms. The implication of the present study is similar to that of investigations of incidental recall by adults (Crowder, 1976): Strategic control processes do not seem to be necessary to produce serial-position effects.

Several researchers have noted a strong relationship between the order in which adults learn items as a list is repeated and the serial position of items that are recalled (Crowder, 1976). The observation suggests the hypothesis that primacy and recency are due to the same underlying mechanism-differential learning. In a sense, the hypothesis involves a regression, because we now need to explain why items at the extremes of the list are learned more rapidly than others. In addition, it appears that the differential-learning hypothesis cannot easily be mapped onto the functions illustrated in Figure 1. These data indicate that the time required to learn a stimulus is monotonic with serial position, such that 
infants quickly become familiar with the first photo they see, take longer to study the middle photo, and take even longer with the iast. Yet Table 1 contains two instances of recognition for the last photo and none for the middle. In a similar vein, it is difficult to argue that primacy and recency are based on differential familiarity with the photos, since the procedures ensured equal total study of each.

Nevertheless, at this juncture we suggest one way in which differential learning could produce the observed effects. It is likely that familiarity accrues not only to an isolable stimulus, but also to the context of events in which the stimulus is experienced. In the present study, items to be remembered were embedded within two distinct sets of objects and events-those outside the apparatus and those of the apparatus itself. With regard to the former, the infants studied the first and last photos juxtaposed with experience outside the apparatus. The middle photo was embedded. We suggest that the extralist stimuli become differentially associated with the end items in the manner described by Ribback and Underwood (1950). That is, the objects and events outside the study episode are associated with the first photo in a forward manner and with the last photo in a backward manner. Ribback and Underwood demonstrated that backward associations are more difficult to establish in serial learning than are forward ones. Consistent with the above account of differential associative strength, the first photo would acquire the strongest association with the outside, the third photo would acquire a somewhat lesser association due to its backward relation to the extralist context, and the second photo would acquire the least association. Although differential leaming could occur with regard to experience outside the apparatus, no such differential learning would obtain with respect to experience with the apparatus itself. Specifically, apparatus cues were simultaneous with all photos and thus could not be differentially associated to any one photo.

When differential association with extralist stimuli is considered in light of the events prior to the recognition test, we can offer an explanation that encompasses both the bowed serial-position function and the labile recency effect. Recall that the apparatus was drawn away from the infant following the familiarization trials, thus reexposing many of the aforementioned extralist stimuli. This procedure could conceivably serve as a prime. That is, the contextual stimuli that occurred both prior to and following each list presentation were similar to the contextual stimuli prior to the recognition test. If the familiarity with an item is relative to its context, as is commonly assumed in studies of animal habituation (Wagner \& Pfautz, 1978) and adult recognition (Anderson \& Bower, 1972), then we would expect the infants' differential response to novelty to follow the pattern of appearance and dissolution that was obtained.

This explanation is clearly speculative at this point. Given the many important differences in paradigms, stimuli, and other relevant factors, it is risky to attempt to explain infants' serial-position effects by borrowing from adult or animal accounts. Nevertheless, contextual variables during acquisition and retrieval are easily manipulated, and their similarity has long been recognized as a broad determinant of retention (Spear, 1978). Moreover, the general principle that associations are contextually dependent may lead to developmental continuity in our explanations of memory process.

For example, a number of studies of short-term retention by 4- to 10-year-old children have employed serialposition recall tasks (Hagen \& Stanovich, 1977). Most researchers have assumed that age-related differences in the shape of the serial-position curve reflect the development of verbal strategies such as labeling and cumulative rehearsal. In the most frequently used paradigm (developed by Atkinson, Hansen, \& Bernbach, 1964), a child is shown a series of pictures of common objects. The pictures are exposed one at a time, turned over, and placed face down, left to right, in a row. At the end of the sequence, the tester asks the child to turn over the picture in the array that matches a probe picture. Primary school children have demonstrated both primacy and recency effects in recall of the location of the target picture, and early accounts attributed these effects to the development of verbal strategies (Hagen \& Stanovich, 1977). The interpretation has not received consistent support, however: Hagen and Kingsley (1968) found serial-position effects but noted recall for initial items was not improved when young children were asked to name items out loud, and Allik and Siegel (1976) noted that the serial-position curves of children who did not spontaneously rehearse nevertheless showed a primacy effect. Recent analyses have indicated that the spatial context of the item to be remembered, rather than the use of verbal mnemonics, is a major determinant of children's performance in this task (Berch, 1978; Siegel, Allik, \& Herman, 1976). The idea is that the items on the far left and the far right of the array are the only ones that have other items on just one side. Thus, as hypothesized to account for the present results, the extralist context provides children a unique cue for remembering items near the beginning and end.

\section{REFERENCES}

Allik, J. P., \& Siegel, A. W. The use of the cumulative rehearsal strategy: A developmental study. Journal of Experimental Child Psychology, 1976, 21, 316-327.

Anderson, J. R., \& Bower, G. H. Recognition and retrieval processes in free recall. Psychological Review, 1972, 79, 97-123.

Atrinson, R. C., Hansen, D. N., \& Bernbach, H. Short-term memory with young children. Psychonomic Science, 1964, 1, 255-256.

Berch, D. B. The role of spatial cues in the probe-type serial memory task. Child Development, 1978, 49, 749-754.

Cornell, E. H. Distributed study facilitates infants' delayed recognition memory. Memory \& Cognition, 1980, 8, 539-542.

CoRnel., E. H. Developmental continuity in memory mechanisms: Suggestive phenomena. In R. Kail \& N. Spear (Eds.), Comparative perspectives on the development of memory. Hillsdale, N.J: Erlbaum, 1983. 
Crowde r, R. G. Principles of learning and memory. Hillsdale, N.J: Erlbaum, 1976.

Ebinghaus, H. E. Memory: A contribution to experimental psychology. New York: Dover, 1964. (Originally published, 1885.)

Fagan, J. F. Infants' delayed recognition memory and forgetting. Journal of Experimental Child Psychology, 1973, 16, 424-450.

FAGAN, J. F. Infants' recognition of invariant features of faces. Child Development, 1976, 47, 627-638.

Fantz, R. L. Pattern discrimination and selective attention as determinants of perceptual development from birth. In A. Kidd \& J. Rivoire (Eds.), Perceptual development in children. New York: International Universities Press, 1966.

Fantz, R. L., Fagan, J. F., \& Miranda, S. B. Early perceptual development. In L. Cohen \& P. Salapatek (Eds.), Infant perception: From sensation to cognition (Vol 1). New York: Academic Press, 1975.

Fantz, R. L., \& Nevis, S. The predictive value of changes in visual preferences in early infancy. In J. Hellmuth (Ed.), The exceptional infant (Vol. 1). Seattle: Straub and Hellmuth, 1967.

Hagen, J. W., \& Kingsley, P. R. Labeling effects in shortterm memory. Child Development, 1968, 39, 113-121.

Hagen, J. W., \& Stanovich, K. E. Memory: Strategies of acquisition. In R. V. Kail \& J. W. Hagen (Eds.), Perspectives on the development of memory and cognition. Hillsdale, N.J: Erlbaum, 1977.

Hunter, M. A., Ross, H. S., \& Ames, E. W. Preferences for familiar or novel toys: Effects of familiarization time in 1-yearolds. Developmental Psychology, 1982, 18, 519-529.

Mranda, S. B. Visual abilities and pattern preferences of premature infants and full-term neonates. Journal of Experimental Child Psychology, 1970, 10, 189-205.

OLson, G. M. An information-processing analysis of visual memory and habituation in infants. In T. Tighe \& R. Leaton (Eds.),
Habituation: Perspectives from child development, animal behavior, and neurophysiology. Hillsdale, N.J: Erlbaum, 1976.

Otson, G. M. Infant recognition memory for briefly presented visual stimuli. Infant Behavior and Development, 1979, 2, 123-134.

RibBack, A., \& UNDERwood, B. J. An empirical explanation of the bowness of the serial position curve. Journal of Experimental Psychology, 1950, 40, 329-335.

Rose, S. A., Gottried, A. W., Melloy-Carminar, P. \& Bridger, W. H. Familiarity and novelty preferences in infant recognition memory: Implications for information processing. Developmental Psychology, 1982, 18, 704-713.

Rovee-Collier, C. K., \& Sullivan, M. W. Organization of infant memory. Journal of Experimental Psychology: Human Learning and Memory, 1980, 6, 798-807.

Siegel, A. W., Allik, J. P., \& Herman, J. F. The primacy effect in young children: Verbal fact or spatial artifact? Child Development, 1976, 47, 242-247.

Spear, N. E. The processing of memories: Forgetting and retention. Hillsdale, N.J: Erlbaum, 1978.

STrauss, M. S. Abstraction of prototypical information by adults and 10-month-old infants. Journal of Experimental Psychology: Human Learning and Memory, 1979, 5, 618-632.

Wagner, A. R., \& Pfautz, P. L. A bowed serial-position function in habituation of sequential stimuli. Animal Learning \& Behavior, 1978, 6, 395-400.

Werner, J. S., \& Perlmutter, M. Development of visual memory in infants. In H. W. Reese \& L. P. Lipsitt (Eds.), Advances in child development and behavior (Vol. 14). New York: Academic Press, 1979.

(Manuscript received December 28, 1982; revision accepted for publication May 27, 1983.) 